\title{
Experiences
}

\section{Plastic surgery for the defects in maxillofacial region after surgical resection of benign tumors}

\author{
Jasur A Rizaev ${ }^{1)}$, Hiromichi Maeda ${ }^{2)}$, Natalya V Khramova ${ }^{1)}$ \\ ${ }^{1)}$ Tashkent State Dental Institute, Tashkent, Republic of Uzbekistan \\ ${ }^{2)}$ Department of Surgery, Kochi Medical School Hospital, Kochi University, Kochi, Japan
}

\begin{abstract}
The short-term results of our surgical technique to close the after surgical resection of benign maxillofacial tumors were retrospectively studied. The results of surgical treatment of 92 patients with maxillofacial tumors in Tashkent State Dental Institute were retrospectively analyzed.

In all cases, plastic closure of the defect and elimination of deformities of the maxillofacial area were performed. The techniques of skin plastics were selected depending on location, size, shape of the defect and other circumstances. Shortterm observation revealed that the wounds healed naturally without the formation of coarse scars and/or deformities of the surrounding tissues.

Our surgical techniques treating defects in maxillofacial area are satisfiable.
\end{abstract}

Keywords: benign tumors, maxillofacial region, defect and deformity, plastic, quality of life.

(Received March 25, 2019; Accepted April 24, 2019)

\section{Introduction}

Surgical resection of tumors in maxillofacial area is sometimes accompanied by defects and various types and degrees of deformities ${ }^{1,2)}$, even if the tumors are benign nature. The reconstruction (closure) of the defects requires certain levels of the technique to avoid the postoperative development of deformities and coarse scars. The purpose of the study is to evaluate our various methods of plastic closure of defects and deformities after removal of the maxillofacial benign tumors.

\section{Methods}

\section{Patients}

The results of surgical treatment of 92 patients with maxillofacial tumors are retrospectively studied.

The consecutive patients who underwent surgery in Tashkent State Dental Institute from March, 2014 to February, 2019 are retrospectively enrolled in this study. This study was approved by the institute review board. We obtained the consent from the patient about this case presentation.

Corresponding author: Hiromichi Maeda, MD, PhD. Department of Surgery, Koch Medical School Hospital, Kochi University, Kohasu, Oko-cho, Nankoku, Kochi, 783 8505, Japan E-mail; hmaeda@kochi-u.ac.jp, Tel: +81-88-880-2370, Fax: +81-88$880-2371$

\section{Surgical technique}

The basic technique is filling the defects by using the surrounding soft tissue. The advantage of using the adjacent tissues is its similarities of color and texture to the removed skin $^{3)}$. There are several types of local plastic interventions: simple closure; closure with mobilized wound edges; closure using counter triangular flaps; use of flaps obtained from legs such as skin, skin and muscular, and flap with vessels.

\section{Results}

\section{Case presentation}

A 70-year-old patient visited the Department of Maxillofacial Surgery of Tashkent State Dental Institute. The diagnosis of angiofibroma of the right infraorbital region was made (Fig. 1A). The operation was performed step-by-step: removal of the tumor (Fig. 1B), mobilization of the flap (Fig. 1C) in order to close the soft tissue defect. In this case, a satisfactory cosmetic effect was obtained due to the mobilized soft tissue flap (Fig. 1D).

\section{Data presentation}

Among 92 included 43 male and 49 female patients. The age of the patents ranged from 18 to 75 years. Sixtynine patients $(75 \%)$ were aged between 35 and 60 years. The diagnosis in these patients was finally established according to the clinical and pathological examination. 

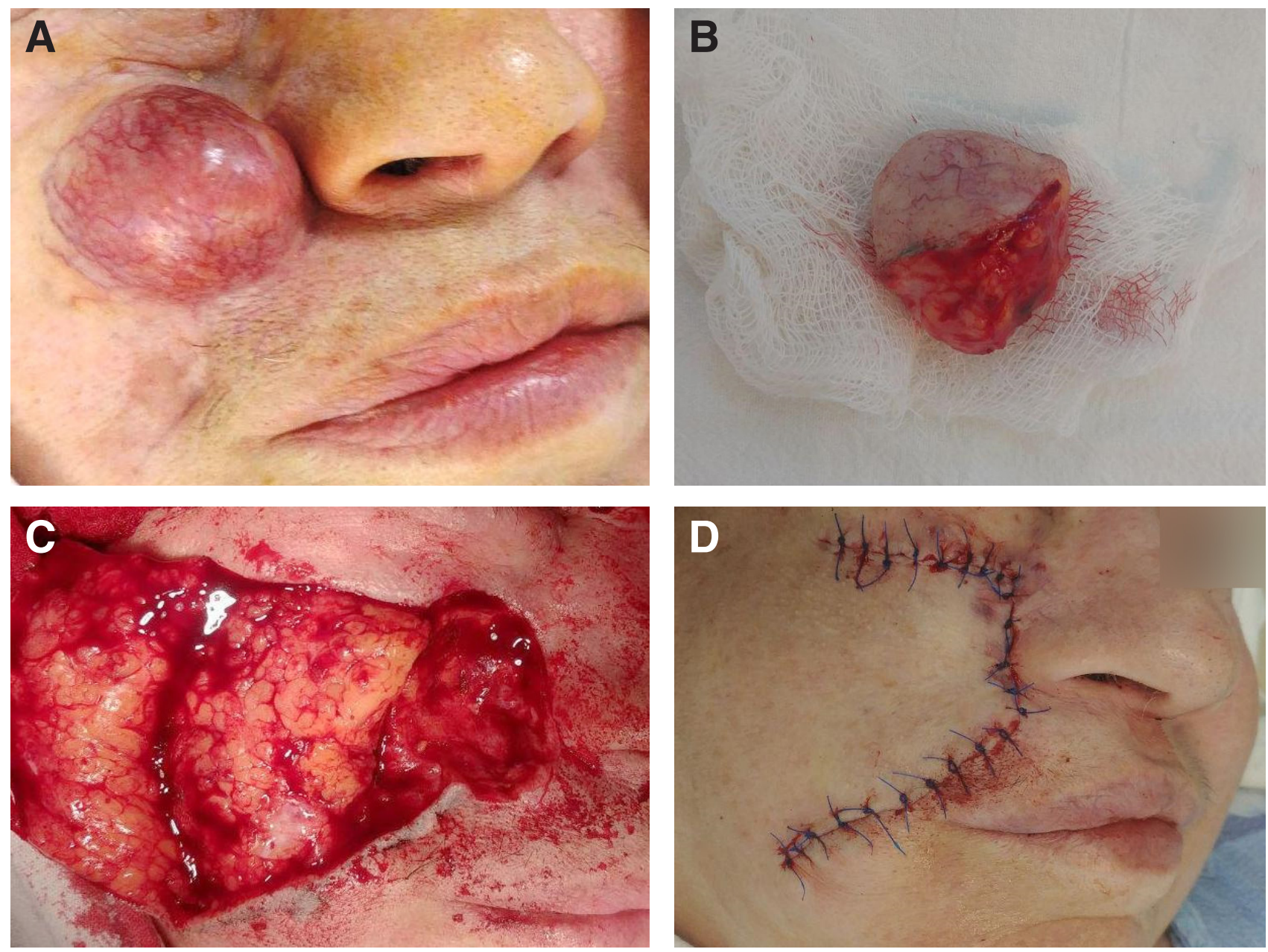

Fig. 1 Stages of angiofibroma removal and plastic closure of the defect.

The choice of the method of skin closures depended on the location, size, shape of the defect and other circumstances. When studying the short-term and long-term results, no complication were observed, such as surgical site infection, flap necrosis or wound dehiscence. The wounds healed as it was intended without the formation of coarse scars and deformation of the surrounding tissues. To date, there are no signs of tumor recurrence in all cases.

\section{Discussion}

As demonstrated in the case presentation, the majorities of the defect closures are performed by using the mobilized edges (flaps) of the wound in our institute. The present study showed the feasibility of our surgical techniques in elimination of defects and deformities after the removal of benign maxillofacial tumors.

\section{Acknowledgement:}

This work is supported, in part, by the non-profit organization Epidemiological \& Clinical Research Information Network (ECRIN).

\section{References}

1) Andrades P, Militsakh O, Hanasono MM, Rieger J, Rosenthal EL. Current strategies in reconstruction of maxillectomy defects. Arch Otolaryngol Head Neck Surg. 2011; 137: 806-12.

2) Mehta RP, Deschler DG. Mandibular reconstruction in 2004: an analysis of different techniques. Curr Opin Otolaryngol Head Neck Surg. 2004; 12: 288-93.

3) Chebotarev S.Ja, Mirzajan GR, Belov I.Ju., Primak NA, Guljaev DA. Ustranenie defektov osnovanija cherepa i srednej zony lica posle hirurgicheskogo lechenija rasprostranennyh kraniomaksilljarnyh opuholej. Siberian journal of oncology. 2016; 15: 62-69. 